\title{
مصير حوار الحضارات في ظل العولمة حلقة نقاشية لتطوير مشروع بحثي
}

تنظيم المعهد العالمي للفكر الإسلامي/مكتب الأردن ومخبر الدراسات العقدية ومقارنة الأديان في جامعة الأمير عبد القادر/الجزائر

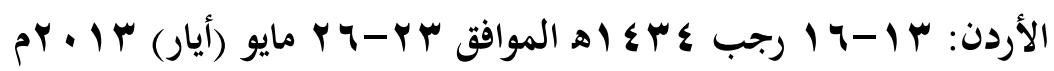

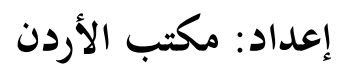

نظـم مخـبر الدراسـات العقديـة ومقارنـة الأديـان جامعـة الأمـير عبــ القـادر للعلـوم

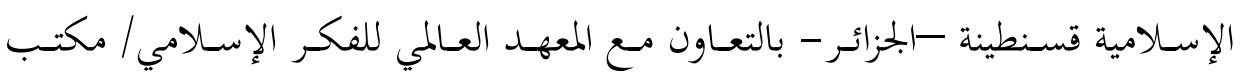

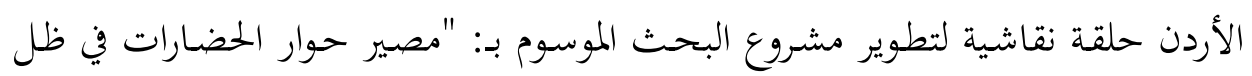

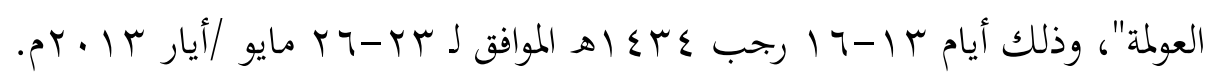
وقـد عُقـدت سـبع جلسـات علميـة؛ خمسـة منهـا لتطوير مشـووع حوار الحضـارات، واثنتـان لتطوير مشـروعي: مسـاق في الفلسفة في الفكر الإسـلامي، ومسـاق سـن قيـام

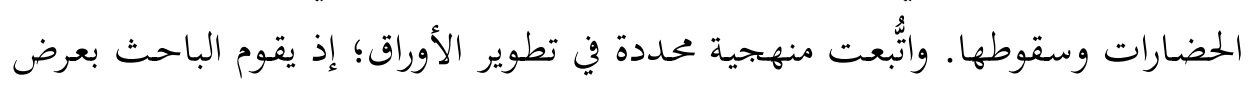

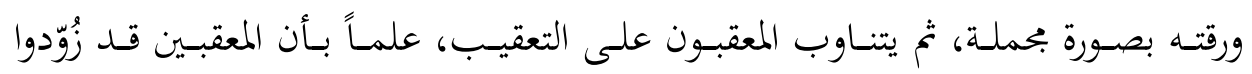
بالأوراق البحثية قبل شهر من انعقاد الحلقة النقاشية.

افتتحـت أشـغال الحلقـة النقاشـية يـوم الخمسيس السـاعة العاشـرة صـباحاً بكلمـة

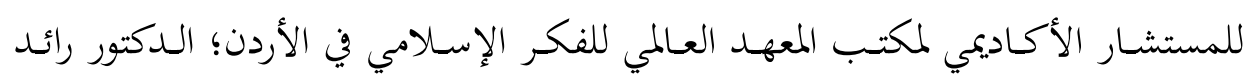

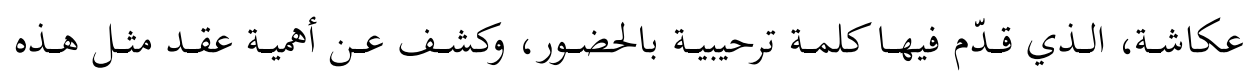

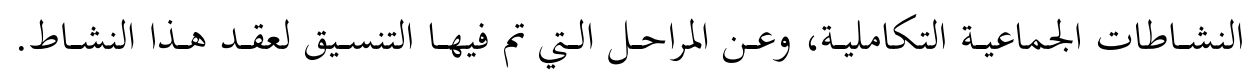

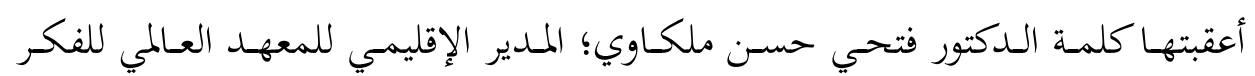
الإسلامي، الذي عرض فيها برنامج العمل، مبيناً أهميته وضرورته للبرامج الجامعية، منوّهاً

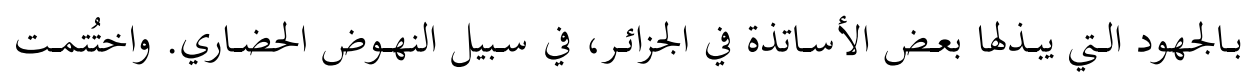


الجلسة بكلمة للدكتور عبد العزيز بو الشعير؛ مدير المشروع، الذي عرض الإطار العام للمشروع؛ مبيناً العناصر الأساسية للمشروع وإشكالياته، وأهدافه ومنهجيته.

انطلقت أشغال الجلسة الأولى بمداخلة الدكتوره زبيدة بن ميسي مـن قسم الفلسفة

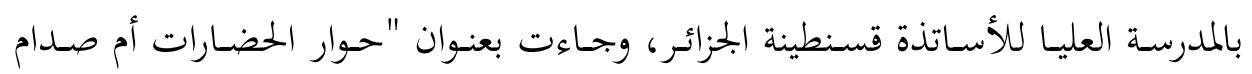

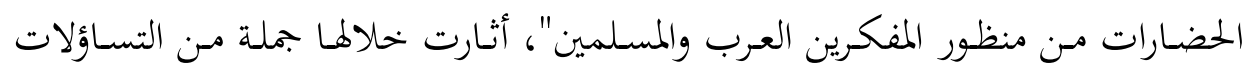

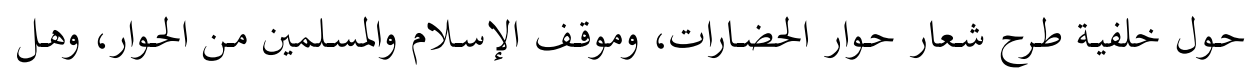

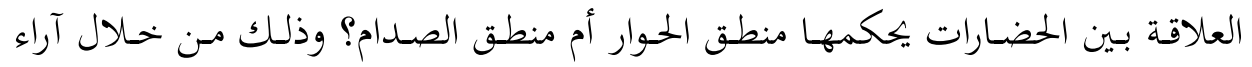
ومواقف بعض المفكرين العرب والمسلمين.

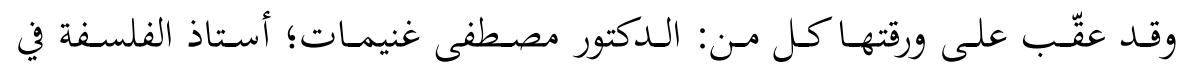

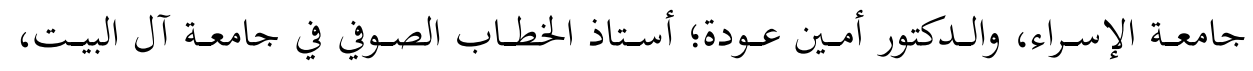

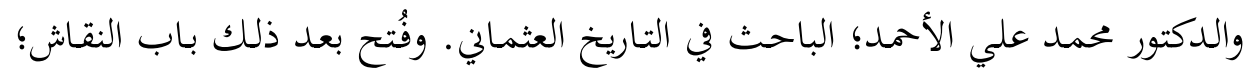
إذ ركزت المناقشات على البعدين: المنهجي والفني للورقة.

أشار الدكتور مصطفى غنيمات إلى أهمية الورقة، ونبَّه إلى ضرورة التصنيف المنهجي

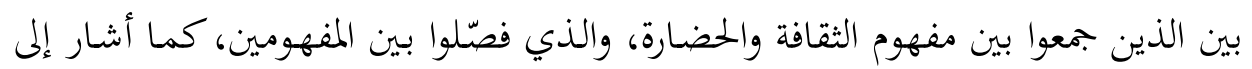

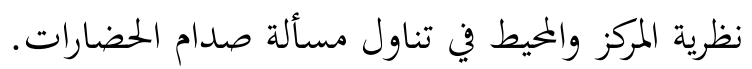

أمـا الـدكتور أمسين عـودة فتـــــــن في تعقيبـه أولويـة الحـوار الـداخلي على الحـوار

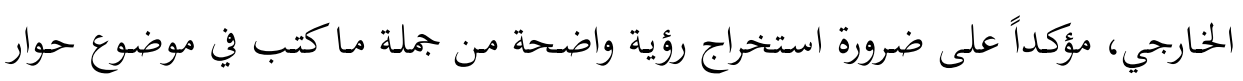
الحضارات وصدامها، وذلك بغية الانتقال من الرؤية والتنظير إلى المسلك والممارسة. مورهة

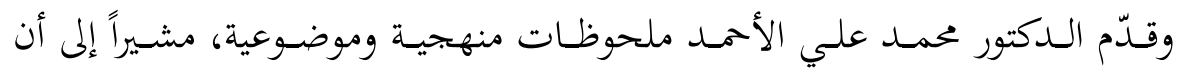

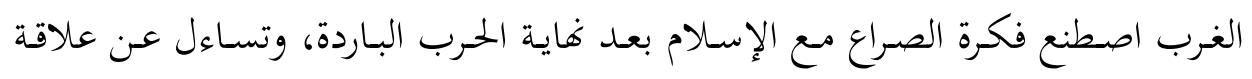

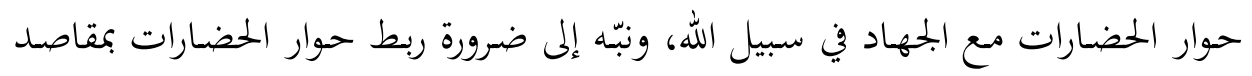

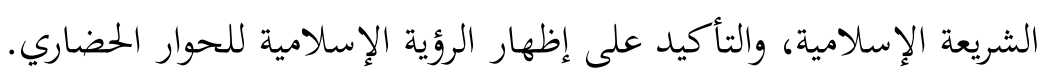
وجـاءت المداخلـة الثانيـة للـدكتور عبـد العزيـز بوالشعير مـن قســم الفلسففة بجامعـة

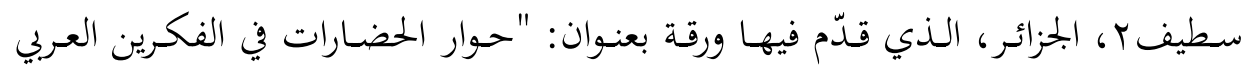


والغربي من أفق التنظير إلى ساحة الممارسة"، تطرق فيها إلى جملة من النقاط منها: مفهوم الفها

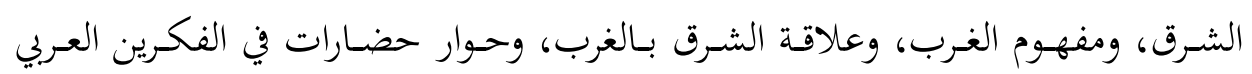

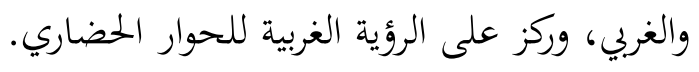

وقد عقب على الورقة كل من الدكتور مازن عصفور ؛ أستاذ النظرية النقدية الفنية في

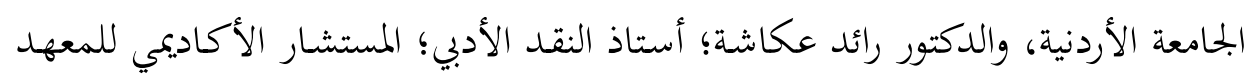

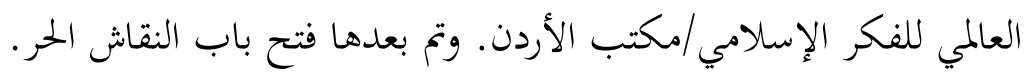

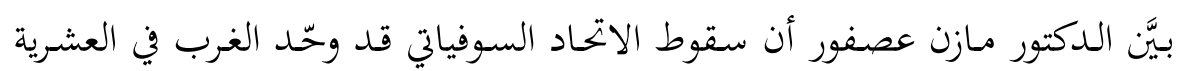

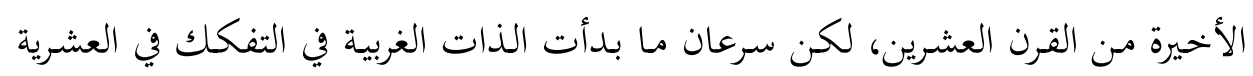

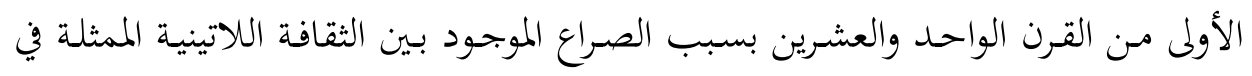

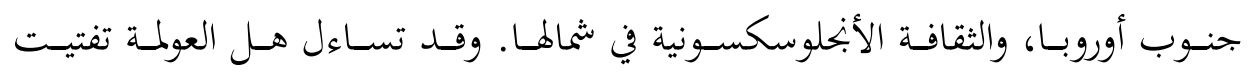

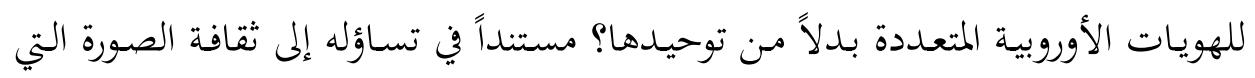

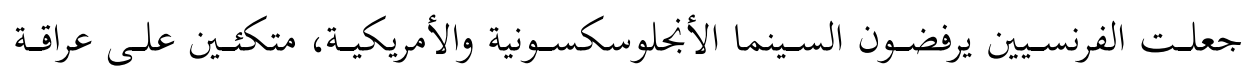
ثقافتهم ذات الأصول اللاتينية.

وفي تعقيبه على الورقة أشار الدكتور رائد عكاشة إلى رفض بعض الأوروبيين لفكرة

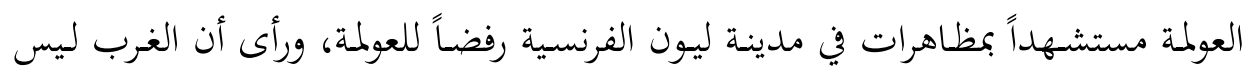

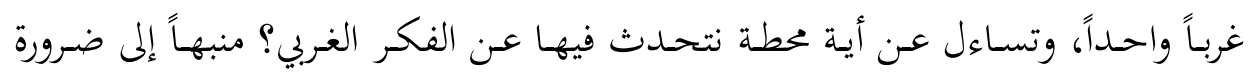

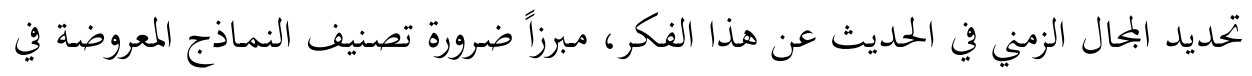

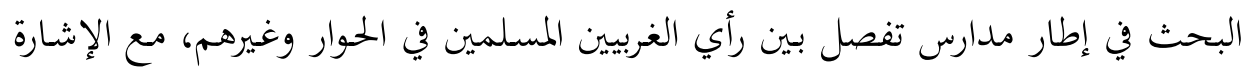

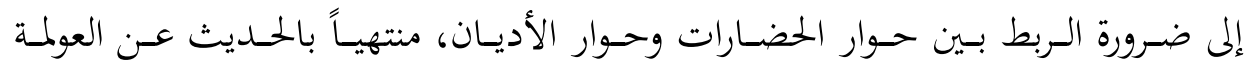

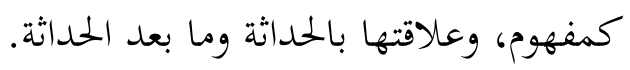

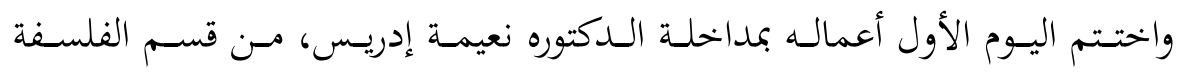

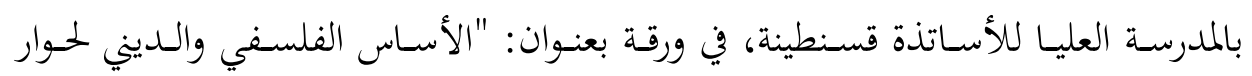

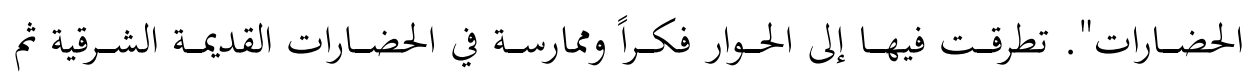

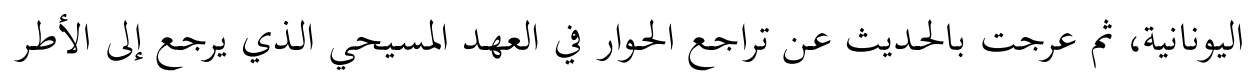

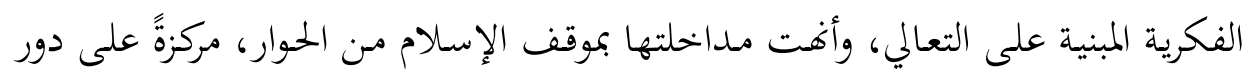


العقـل في الفكــ الإسـلامي، خاصـة آليـة الاجتهـاد التي فِّلـت حركـة الحـوار داخليـاً وخارجياً.

وعقّب على الورقة كل من الدكتور خالد الجمب؛ أستاذ النقد والبلاغة في جامعة البترا الأردنية، والدكتور حسام اللحام؛ أستاذ البلاغة في جامعة الزيتونة الأردنية.

أشار الدكتور خالد الحبر في تعقيبه إلى أن الحوار منطق الضعفاء من جهة، وإفلاس منظومة القيم الغربية والنظم المادية من جهة أخرى، داعياً إلى ضرورة التفكير الإيجابي تجاه

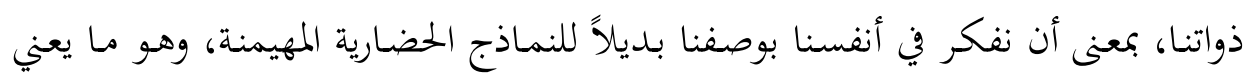

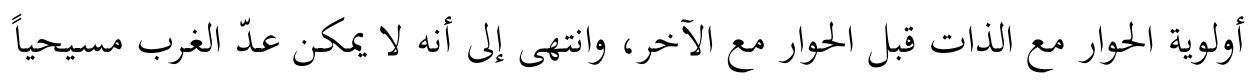
بالأساس بالنظر إلى علمانيته التي تقوم على الفردانية، والديمقراطية، والليبرالية. وفي تعقيبه على الورقة أشار الدكتور حسام اللحام إلى ضرورة ضبط مفهوم الحوار

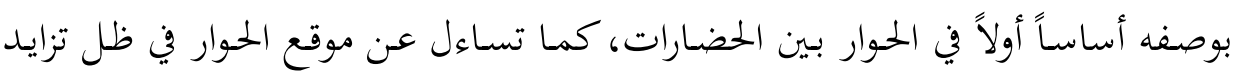

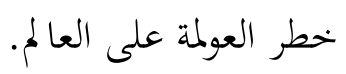
وأعقب ذلك مناقشات الحضور.

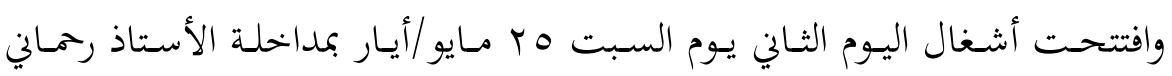

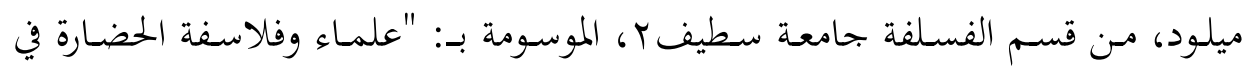

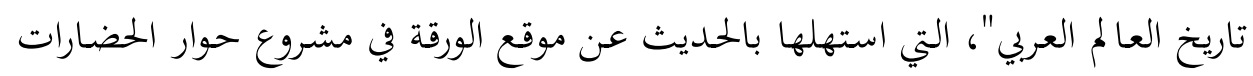

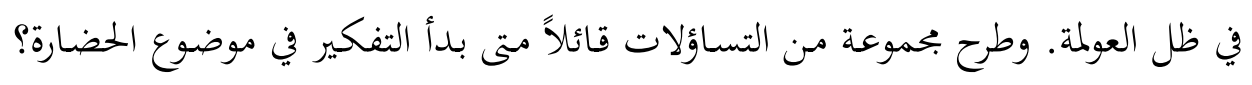

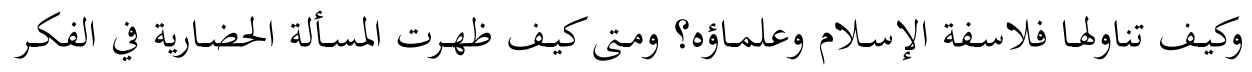

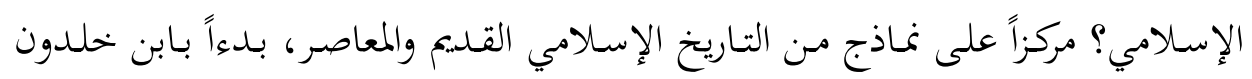
ومالك بن نبي، وانتهاء بشخصية أوروبية متميزة هي: علي عزت الإني بيجوفيتش. وعقب على الورقة كل من الدكتور محمد علي الجندي؛ أستاذ الفلسفة الإسلامية في

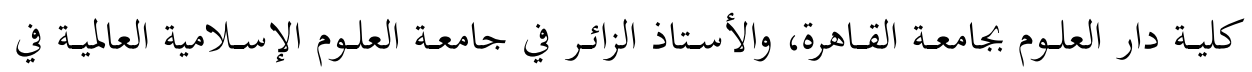
الأردن، والدكتور عليـان الجـالودي؛ أستاذ التاريخ الوسيط في جامعـة آل البيت. تلتهما 


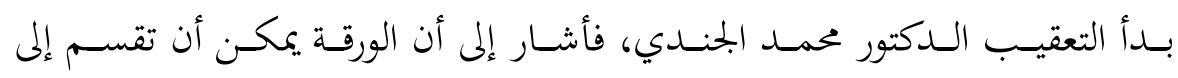

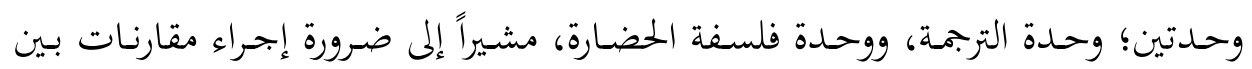

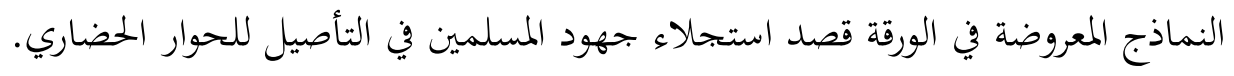
وتلا ذلك تعقيب الدكتور عليان الجحالودي؛ إذ ركّز على تلازم الحضارة والتاريخ،

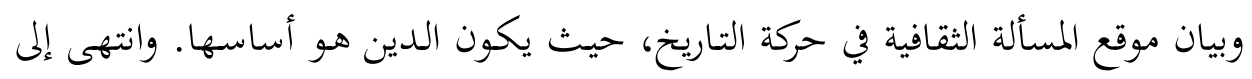

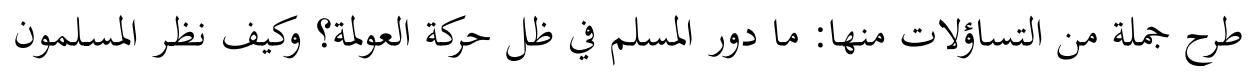
إلى الآخر؟ وكيف كان الآخر ينظر إلينا؟

واختتم اليوم الثاني بمداخلة الدكتور عبد الرزاق بلعقروز، مـن قسم الفسلفة جامعة

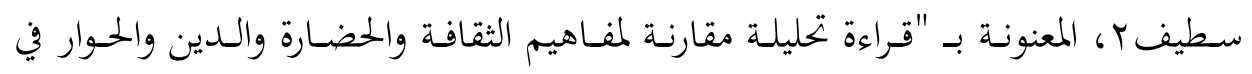

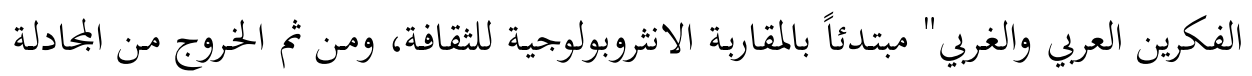

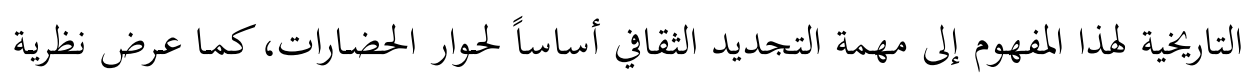

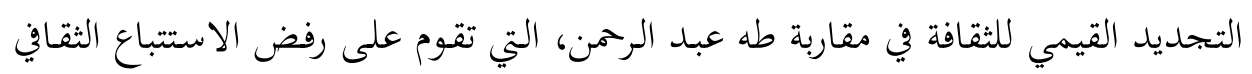

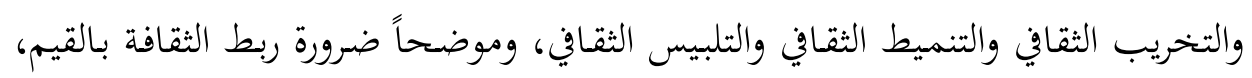

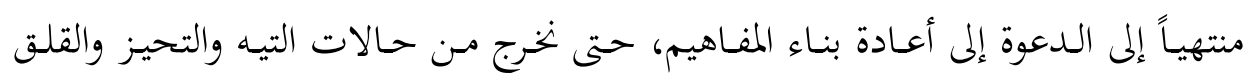
المفاهيمي.

وقد عقّب على هذه الورقة كل من: الدكتور عزمي طه؛ أستاذ الفلسفة في جامعة آل البيت، والدكتور حمود عليمات؛ أستاذ علم الاجتماع في الجامعة الأردنية.

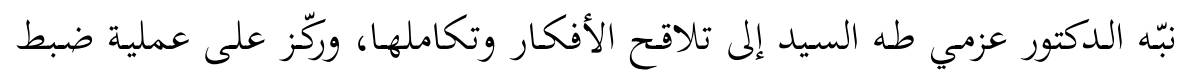

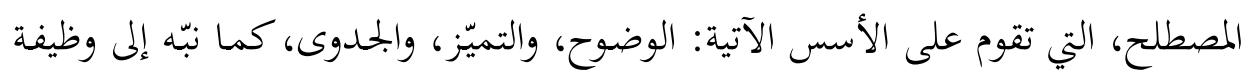

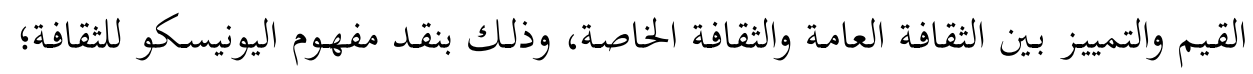

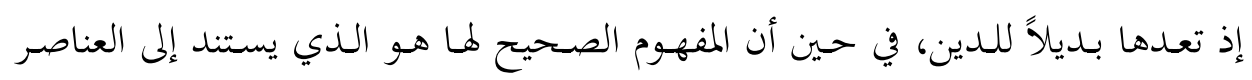
الآتية: البصيرة، والهداية، والتوجيه.

تلا ذلك تعقيـب الـدكتور حمـود عليمـات، فبيّن أن الثقافـة هي بحمـوع الكسـب

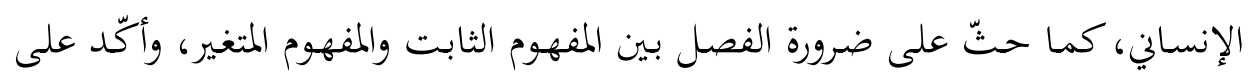


عدم إمكانية تصدير قيم فارغة للغرب، بل دعا إلى ضرورة تقديم نمودج حضاري ثقافي

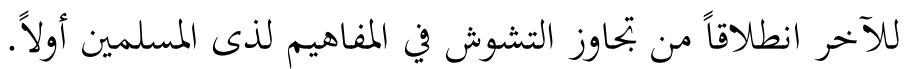

وفي اليوم الثالث مـن هــه الأيـام العلميـة نظّمـت ورشـة عمل حسول تطوير مسـاق

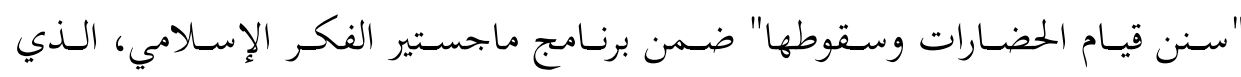

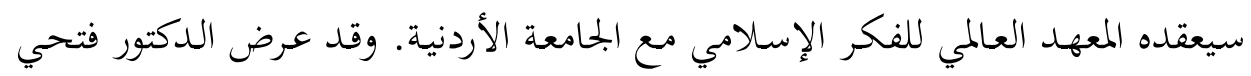

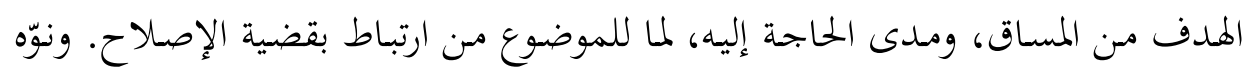

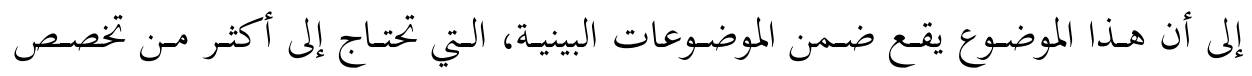

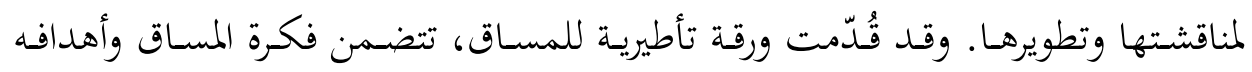

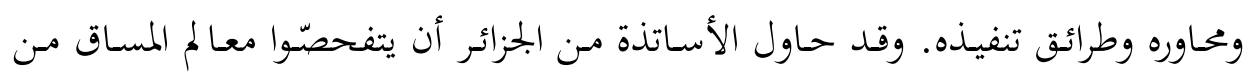

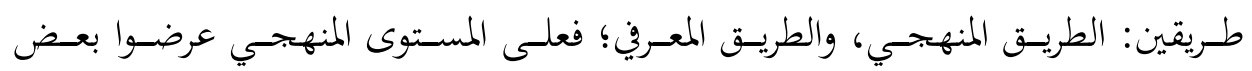

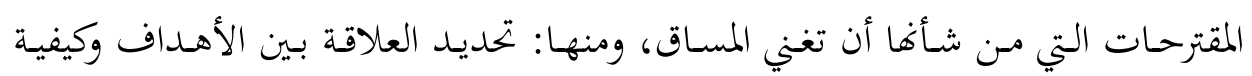

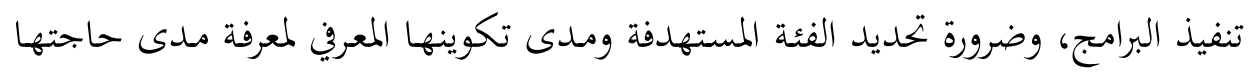

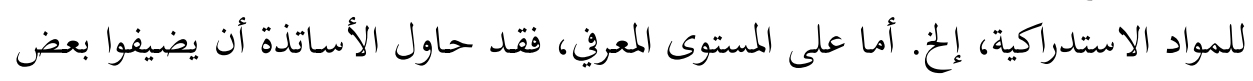

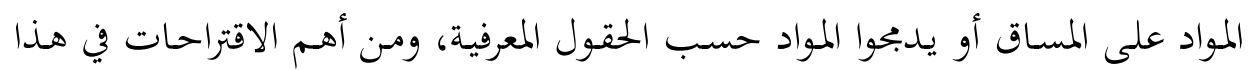

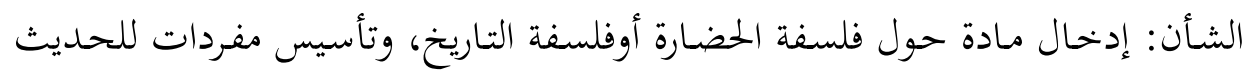

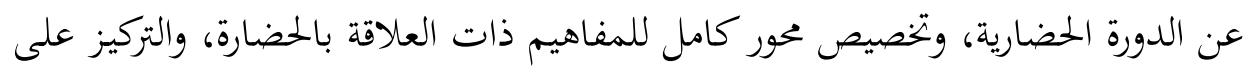
موضوع بناء الحضارات، إلخ.

واختُتمـت الأيسام العلميـة بحلقـة نقاشـية حسول تطوير مسـاق في الفلسفة في الفكر الإسلامي؛ إذ قام الدكتور فتحي بتقـديم تصور مكتوب حول المساق الذي بلوره أثناء

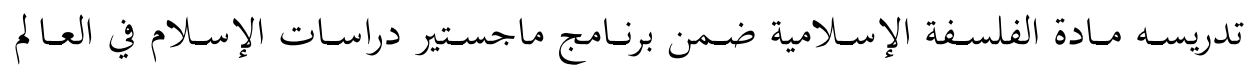

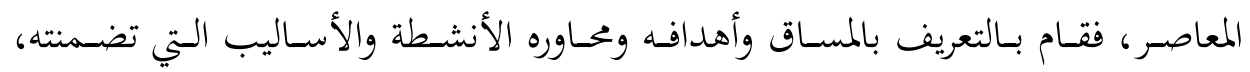

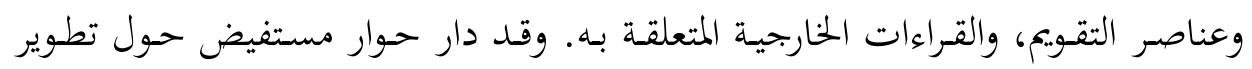

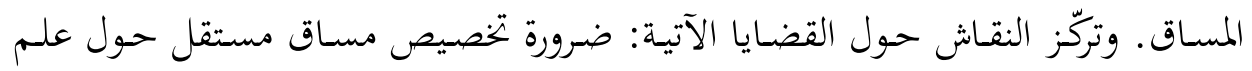

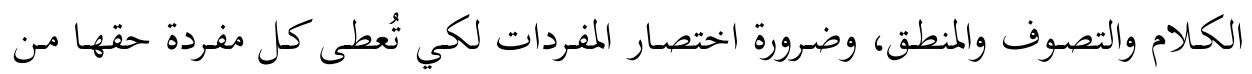

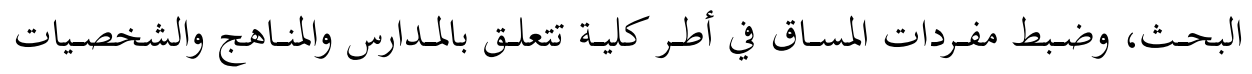

